\title{
1.Lig Goalball Oyuncularının Örgütsel Stres Davranışlarının İncelenmesi
}

\author{
DOI: $10.26466 /$ opus.591787
}

Suzan Dal* - Burçak Keskin** - Eray Yurtseven*** - C. Nihal Yurtseven ****

* Okt. Dr. İstanbul Üniversitesi-Cerrahpaşa, Spor Bilimleri Fakültesi, Avcılar / İstanbul / Türkiye E-Posta: suzann.dal@gmail.com

ORCID: 0000-0002-7732-9846

** Doç. Dr. İstanbul Üniversitesi-Cerrahpaşa, Spor Bilimleri Fakültesi, Avcılar / İstanbul / Türkiye

E-Posta: burcakk@istanbul.edu.tr

ORCID: $0000-0003-4313-7720$

*** Doç. Dr. İstanbul Üni., Cerrahpaşa Tıp Fak., Dahili Tip Bil. Bö., Halk Sağ. A. D./ İstanbul / Türkiye

E-Posta: eyurt@istanbul.edu.tr

ORCID: $\underline{0000-0003-0565-6407}$

**** Okt. Dr. İstanbul Üniversitesi-Cerrahpaşa, Spor Bilimleri Fakültesi, Avcılar / İstanbul / Türkiye

E-Posta cny@istanbul.edu.tr

ORCID: 0000-0001-8201-0752

Öz

Çalı̧manın amacı, 1. Lig goalball oyuncularının örgütsel stres faktörlerinden ne ölçüde etkilendiklerini belirlemektir. Yapılan çalışmada goalball oyuncuları üzerinde antrenör davranışı, sağllk ve beslenme, yönetim ve finans, karara katılım ve seyirci davranışı stres faktörleri ölçülerek karşılaştırılmıştır. Araştırma örneklemini 1. Ligde oynayan toplam 97 goalball oyuncusunun oluşturduğu çalısmada, Üzüm H. ve ark.(2010) tarafından geliştirilen, Elit Sporcu Örgütsel Stres Ölçeği kullanılmıştır. Çalışmamızda, bulguların değerlendirilmesinden elde edilen sonuca göre katılımcların Örgütsel stres alt boyutlan incelendiğinde antrenör davranışı alt boyutu $X=3.08$, yönetim ve finans alt boyutu $X=3.04$, sağllk ve beslenme alt boyutu $X=3.11$, seyirci davranışı $X=3,06$ ve karara katıl alt boyutu $X=3.23$ olarak belirlenmiştir. Örgütsel stres ölçeği Toplam Cronbach Alpha iç tutarllik değeri $\alpha=0.823$ olarak belirlenmiştir. Bu sonuç, daha önce oluşturulmuş olan ölçeğin çalışmamızda fiziksel engelli sporcuların örgütsel stres düzeylerini ölçmede yeterli olduğunu göstermektedir. Örgütsel stres ölçeği Alt boyutların Cronbach Alpha iç tutarlllk değerleri incelendiğinde Antrenörün Davranışları alt boyutu $\alpha=0.768$, Yönetim-Finansman alt boyutu $\alpha=0.811$, Sağllk Beslenme alt boyutu $\alpha=0.825$, Seyirci davranışları alt boyutu $\alpha=0.855$ ve Karara katılma alt boyutu $\alpha=0.771$ olarak belirlenmiştir. Çalı̧̧mamızda örgütsel stres Toplam Cronbach Alpha iç tutarlilık değgerleri ise $\alpha=0.828$ olarak bulunmuştur. Elit sporcu örgütsel stres ölçeği sonuçlarının dağılımının normalliği (Shapiro-Wilk) testi yapıldığında elde edilen sonuçlar anlamlılık düzeyi değerlerinin 0.05 'ten büyük olması elde edilen ölçek değerlerinin dağılımlarının normal dağılım olduğunu göstermektedir. Analizlerde parametrik ölçümler kullanılmıştır. Çalışmamızda verilerin analizinde frekans, $t$-testi ve anova ölçümleri yapılmıştır. Bu sonuçlardan goalball oyuncularmın en fazla etkilendikleri örgütsel stres faktörü karara katılım olduğu belirlemiştir. Özellikle engelli sporcularm bu düşüncelere sahip olmalar durumunda performanslarmm olumsuz etkileneceği için yönetimin bu konuda daha hassas olması gerektiği sonucuna varılmıştır.

Anahtar Kelimeler: Engelli sporcular, Goalball, Örgütsel stres 


\title{
Analyzing Organizational Stress Behavior of First League Goalball Players
}

\begin{abstract}
The aim of our study is, the organizational stress levels of sports players with disabilities were measured and compared. Specifically, the stress factors of trainer behavior, health and eating, management and finance, agreeing decision, and audience behavior on goalball players were measured and compared. In this study with a sample of 97 goalball players in first league, the organizational stress scale for elite sports players was examined by Üzüm H. et.al.(2010). This study found that upon analysing the sub-dimensions of organizational stress, the Behavior of Trainer mean score was $X=3.08$, the Management-Financing mean score was $X=3.04$, the Eating Healthy mean score was $X=3.11$, the Audience behaviour mean score was $X=3.06$, and the Agreeing Decision mean score was $X=3.23$. The total Cronbach's Alpha internal consistency of organizational stress scale was found to be $\alpha=0.823$. This result showed that this scale was sufficient to measure the organizational stress levels of sports players with physical disabilities. When the Cronbach's Alpha internal consistency values of sub-dimensions of the organizational stress scale were analyzed, the Trainer Behavior was found to be $\alpha=0.768$, the Management-Financing sub-dimension was found to be $\alpha=0.811$, the Eating Healthy sub-dimension was found to be $\alpha=0.825$, the Audience Behavior was found to $b e \alpha=0.855$, and the Agreeing Decision sub-dimension was found to be $\alpha=0.771$. In this study, the Total Cronbach's Alpha internal consistency of organizational stress scale was found to be $\alpha=0.828$. The normal distribution (Shapiro-Wilk) test applied to the results of elite sports player organizational stress scale showed a significance value of 0.05 or more, indicating that the scale values showed normal distribution. The parametric measurements were used in this analysis. Frequency, t-test, and ANOVA statistics were used for the data analysis of this study. Based on these results, it was found that goalball players highest stress for the agreement on decisions subscore among the organizational stress factors. Because the thoughts of sports players with disabilities would negatively affect their performance, it is especially important to be gentle about this topic.
\end{abstract}

Keywords: Sports players with disabilities, Goalball, Organizational stress 


\section{Giriş}

Tanım olarak görme engeli sporcular için eğitimsel başarılarını negatif yönde etkileyen ve düzeltilmesi çok zor görme kaybı olarak ortaya çıar (Craft, 1995). Sporcuların engel durumu, engellilik derecesine göre farklı branşlarda spor yapmalarına olanak sağlar. Görme engelli sporcular arasında en fazla tercih edilen spor dalları bowling, satranç, atletizm, torball, futbol ve en önemlisi de goalball'dur (Maggill, 1980). Bu spor branşları görme engelli sporcularımızın yaşamlarında kas kontrolü, güven, sporcuların hareketlerinde serbestlik ve özgürlük, koordinasyon sağlama, denge ve serbest zamanlarını sağlıklı bir biçimde geçirmelerine yaşamlarını sağlıklı bir şekilde idame etmelerine yardımcı olmaktadır. Görme engelli sporcularımızda spor, görme kaybı sebebi ile kendi çevresinde zarar görebileceği korkularının birazda olsa giderilmesi ve bu bireylerimizin başka kişilere muhtaç olmadan bağımsız bir şekilde yaşamlarını idame ettirebilmelerini sağlamaktadır (Connell, 2000). Görme kaybı olan bireylerde direk fiziksel ve motor özelliklerinin kaybına bununla birlikte koordine olamayan vücut gelişimsel kayıpların ortaya çıkmasına da neden olmaktadır. Bu gelişmelerle birlikte bireyde hareketsizlik, çevre ile olan iletişime ket vurması ve çevreyi de manipüle etmesi olarak ortaya çıkar. Motor gecikme sonradan görme yetisini kaybeden kişilerde görülmezken, daha önce görme yetisini kaybetmiş bir bireyde motor gecikmesi görülür (Lieberman, 1998). Görme engelli sporcularımızın en yaygın olarak yaptı̆̆ı spor branşının başında goalball sporu gelmektedir. Bu spor dalının ortaya çıkması İkinci Dünya savaşına dayanmaktadır. İkinci Dünya Savaşının ardından görme yetilerini kaybeden Alman askerlerin rehabilitesi için düzenlenmiş ve geliştirilmiş bir oyun olarak meydana çıkmıştır. Takımdaki oyuncular farklı görme derecelerine sahip oldukları için göz bandı kullanırlar (Ganley,2001). Görme dereceleri; B1 oyuncusu (Bu oyuncular tamamen göremez, 1şı1 algısı mevcut olmasına karşın herhangi bir mesafeden de el şeklini tanıyamazlar ), B2 oyuncusu (Bu oyuncular elin şeklini algılar fakat görme yetisi; 20/600 (\% 3) den daha iyi değildir), B3 oyuncusu (Bu oyuncular görme açısı görsel açıları alanda 5 dereceden azdır) şeklindedir. 5 ile 20 derece arasında görme açısı olan sporcular; 20/600 (\% 3) ile 60/600 (\% 10) görme yetisine sahiptirler (Özer, 2005). 
Konusu stres olan çalışmaların son yıllarda artış ve revaçta olmasına karşın, normalde stres, stres ile başetme ve yaşama, stres deneyimi yeni bir kavram değildir. Bunun nedeni ise, zaten günlük hayatamızda sık sık karşımıza çıan kişiler arasında gerilime neden olan yaşanılanlar ve olaylar daima bulunmuş, insanlar bu yaşanılan olaylara daima maruz kalmışlar ve hala süregelen bir olgu olarak güncelliğini daima koruyan bir kavram olmuştur. Stres kelimesi ile ilk olarak fizik biliminde bahsi geçmiş, farklı disiplinlerde farklı anlamlar yüklenerek kullanılmaya başlanmıştır. Stresin psikolojik açıdan yapılan tanımı, bizim için en önemli olanıdır. Stres psikolojik tanımı ile ifade edilirse "zorluk" yada "sıkıntı" anlamını taşıyan Fransızca'da, Ortaçağ İngilizcesinde geçen "straisse" yada "stres" sözcülerinden meydana gelmektedir. Bu sözcügün kökeni kuvvet ile muhtemel Latince'de "çekip germek" anlamından çıkan "stringere" kelimesinden gelmektedir (Graham ve Helen, 1999). İsteklerimize karşı gösterdiğimiz tepkidir stres. Birçok birey, başkaları tarafından kendisine yaptığ 1 davranışlardan ötürü ortaya stresin oluştuğunu düşünür. Özüne indiğimizde aslında stres; kendimizin aşırı istek ve duygularımız sonucunda ortaya çıkan durumlara verdiğimiz birçok tepkidir. Birey üzerinde aşırı psikolojik talep ve aşırı fizyolojik talep meydana getiren uyarıcıya karşı, bireyin uyum gösterme tepkisidir stres (Çukur ve Mürsel, 2001). Bu bağlamda stres faktörü sporcuların kazanacakları başarılara, fiziksel enerjilerine, eğlence ve zevklerine daima zarar verebilecek bir faktör olduğu unutulmamalıdır. Bu faktör sporcularımıza öz güvenlerine zarar verip, kendilerinin yeteneksiz bir sporcu olduğu hissine kaptırabilir. Psikolojik stres faktörü sporcularımızda yıllarca çalışıp elde etmiş oldukları beceri ve yeteneklerini ortaya koymalarına mani olabilir, akış deneyimlerini engelleyip, daha ileri boyutta sporcuların sakatlanarak meslek hayatlarını riske bile sokabilir. Stres insan için gizli bir hastalık gibidir. Bu bağlamda sürentremanın ortaya çıkmasına sebep olur. Stresin meydana getirdiği bir çok olumsuz durumlar sporcuların dışında antrenör, diğer yardımcı asistanlar, teknik direktörler ve sporun içinde, değişik kademelerde görev yapan kimler var ise bu bireyleri de doğrudan etkileyebilir. Stresi ve stres yönetimini, başa çıkma uygulamalarını çok iyi bilip yönetmemiz bize savunmasız kalmaktan kurtaracaktrr(Altungül, 2006). 
Örgüt stresi ise örgüt üyelerine fiziksel, psikolojik ve davranışsal sapmalara neden olmaktadır. Stresin olumsuz etkilerinin olduğu gibi bazı durumlarda olumlu sonuçlara da sebep olmaktadır. Örnek vermek gerekirse, stresin hiç olmadığı bir çalışma ortamında iş performansı düşer ve mücadele hırsı yok olur. Ne zamanki çalışma ortamında stres yükselir o zamanda stresin yükselmesi ile çalışanın iş performansında artış görülmeye de başlar. Stres çalışma ortamlarında gerektiği gibi yönlendirilirse, kurum ve kişinin amaçlarının gerçekleşmesini engelleyen faktör ve faktörlerle mücadelede tam tersi olarak kişiyi motive edici bir durumu meydana getirir ve önemli bir rol de üstlenir (Yllmaz ve Ekici, 2003). Buradaki en önemli ve hassas nokta stresin güdüleyici türünü bulup, bunun yanında da zararlı olan genelde stres terimi ile bağdaşan yıkıcı olan stresten korunma ve kendini kollama yollarını öğrenerek, kişinin öz yaşamından haz almasını sağlama ve her alanda verimli olmasını sağlayabilmektir (Şahin, 2005). Birey örgüt ortamında belirli görev ve rollerini yerine getirmekle yükümlü iken, bireysel stres etkenleri ile örgüt ortamından kaynaklı örgütsel strese de maruz kalmaktadır (Arslan, 2007). Her mesleğin kendine özgü stres kaynakları olabileceği gibi genel olarak örgütsel stresin sebepleri arasında çalışanın kişiliğinden kaynaklanan sebepler, çevresel faktörlerden kaynaklanan sebepler, rol çatışması ve belirsizlik gibi sebepler gösterilmektedir( Ironson, 1992). Bunun yanında bireyin fiziki durumundan kaynaklanan sebepler de örgütsel stresi artt1rabilir. Bedensel rahatsızlığı olan bireylerin bedensel rahatsızlığı olmayan bireylere oranla stres belirtileri daha yüksektir (Batıgün ve ark. 2011). Bununla bağlantılı olarak çalışma ortamında oluşan stres sağlıklı bireylere oranla fiziksel engeli olan bireyleri daha fazla etkileyebilir. Bedensel engelin vermiş olduğu stresin yanında profesyonel olarak spor yapan bireylerin sporun yapisindan kaynaklanan rekabet veya devamlı daha fazlasinı hedeflemek Bireyin daha fazla strese maruz kalmasina sebep olmaktadır (Balcığlu Ve Doğrul,2011). Doğuştan veya sonradan oluşmuş olan engellilik, organ veya organda meydana gelen işlevsel kayıplarına bağlı olarak kişinin yaşam kalitesini olumsuz yönde etkilemektedir. Bu kayıpların kişisel ve toplumsal sonuçlarının yaşam koşullarını etkilemesi ile engelli kişinin yaşama, yaşamını sürdürme, korunma, bakım ve iyileştirme, eğitim, gelişme ve sosyal hayata katılım sağlama imkânları sınırlanmaktadır. Dolayısıyla söz konusu problemleri yaşayan 
kişilerin, işlev bozukluğu ya da bedensel bir yakınmasının olduğunun göz önünde bulundurulması, daha iyi sonuçlar sağlayacak yardım beklentilerine öncülük edebilir (Cantwell vd. 2014). Başarmanın anlamı engelliler için çok özel ve önemlidir. Çalışma yaşamında olan engelli bireyler, kendilerini örgütsel stresten uzak ve bunun yanında rahat bir birey olarak kendilerini görmekte iken, çalışma hayatına sonradan dâhil olan engelli bireyler ise çalışma hayatına dâhil olması ile iyileşme ve tedavi süreçlerinde çalışma hayatının önemli bir rol aldığı gözlemlenmiştir. Bu olumlu durumlar karşısında ise engelli bireylerimiz için çalışma hayatının bazı zorluklarıda vardır. Sosyalleşme, işe alım konularında engelli bireylerimizin ayırımcılığa maruz kalması maalesef olumsuz yönlerinden birkaç tanesidir. Bu durumlar engelli bireylerimizde ekstra stres sebebi olarak düşünülebilinir (Tokoğlu, 2011).

Bu çalı̧̧mada, yukarda bahsedildiği gibi maruz kalınan stres faktörlerinden kaynaklı olarak görme engelli sporcularımızın stres düzeyleri incelenmiştir. Araştırmamızda görme engelli sporcularda stres yaratan durumların ortaya konması amaçlanmıştır. Engelli sporcuların çalıştırıcı, takım arkadaşları, aile ve sosyal çevresinden kaynaklanan stres seviyelerinin ortaya çıkması açısından önem teşkil etmektedir. Araştırma sporcu ve yöneticilere önemli bir ışık tutacağından bu açıdan bakıldığında büyük önem arz etmektedir. Engelli sporcularımızın (Goallball) fiziksel engellerinden meydana gelen stres faktörleri daha fazla olması nedeniyle daha fazla örgütsel stres yaşayabilecekleri düşünülebilir. Bu amaçla belirlenen stres faktörleri için önlemler alınarak goalball oyuncularının yaptıkları spor ile iyileşme ve topluma kazanma durumlarına katkı sağlayacağı ilişkilendirilebilir. Örgütsel stres kaynakları bireyin içinde bulunduğu kurumla, yaptığı ile ilgili olarak değişiklik göstermektedir. Örneğin bir sporcunun örgütsel stres kaynakları nedir diye baktığımızda seyirci davranışı, antrenör davranışı gibi diğer bir çok örgütte olmayan faktörler girmektedir. Çalışmamız görme engelli (Goallball oyuncuları) sporcuların en fazla hangi örgütsel strese sahip oldukların inceleyip bu konu ile ilgilenen kişilere ışık tutacağı amaçlanmaktadır. 


\section{Yöntem}

$\mathrm{Bu}$ araştırmanın çalışma grubunu 1.ligde oynayan 97 goalball oyuncusu oluşturmaktadır. Katılımcıların yaş ortalamaları 23'tür. Çalışmada veri toplama aracı olarak anket tekniği kullanılmıştır. Çalışmamızda Üzüm H. ve ark.(2010) tarafından geliştirilen, Likert Tipi Elit Sporcu Örgütsel Stres Ölçeği (ESÖSÖ) değişiklik yapılmadan araştırmada kullanılmıştır. Örgütsel stres ölçeği Toplam Cronbach Alpha iç tutarlılık değeri $\alpha=0.823$ olarak belirlenmiştir. Bu sonuç, daha önce oluşturulmuş olan ölçeğin çalışmamızda fiziksel engelli (Goalball oyuncuları) sporcuların örgütsel stress düzeylerini ölçmede yeterli olduğunu göstermektedir. Örgütsel stres ölçeği Alt boyutların Cronbach Alpha iç tutarlılık değerleri incelendiğinde Antrenörün Davranışları alt boyutu $\alpha=0.768$, YönetimFinansman alt boyutu $\alpha=0.811$, Sağlık Beslenme alt boyutu $\alpha=0.825$, Seyirci davranışları alt boyutu $\alpha=0.855$ ve Karara katılma alt boyutu $\alpha=0.771$ olarak belirlenmiştir. Çalışmamızda örgütsel stres Toplam Cronbach Alpha iç tutarlılık değerleri ise $\alpha=0.828$ olarak bulunmuştur. Araştırmadan elde edilen verilerin analizinde SPSS 20 paket programı kullanılmıştır. Elit sporcu örgütsel stres ölçeği sonuçlarının dağılımının normalliği (Shapiro-Wilk) testi yapıldığında elde edilen sonuçlar anlamlılık düzeyi değerlerinin 0.05 'ten büyük olması elde edilen ölçek değerlerinin dağılımlarının normal dağılım olduğunu göstermektedir. Analizlerde parametrik ölçümler kullanılmıştır. Verilerin değerlendirilmesinde istatistiki yöntem olarak; betimsel istatistikler (frekans, aritmetik ortalama, standart sapma); t testi, tek yönlü varyans analizi (ANOVA) testleri kullanılmıştır.

\section{Bulgular}

Tablo 1'de Cinsiyet değişkenine göre, sporcuların \%67'sini (n=65) erkek, \%33'ünü ( $n=32)$ ise kadın sporcular oluşturmaktadır. Medeni durum değişkenine göre \%75,3 ( $\mathrm{n}=73)$ sporcunun bekar, \%24,7 ( $\mathrm{n}=24)$ sporcunun evli, olduğu görülmektedir. Sporcuların \%10,3'u (n=10) ilköğretim, $\% 63,9^{\prime}$ i (n=62) lise, \%6,2'si (n=6,2) önlisans, \%18,6'si (n=18) lisans, \%2'si $(n=1)$ lisansüstü eğitimli sporculardır. Katılımcıların \% 75,3'ünü $(n=73)$ engel durumu doğuştan olanlar, \%24,7'sini $(n=24)$ sonradan olanlar 
oluşturmaktadır. Katılımcıların spor yılına baktığımızda \% 36.' 'i (n=35) 0-5 yıl, \% 44.4.' ü (n=44) 6-10 yıl, \% 18,6's1 (n=18) ise 11-15 yıl arasinda olduğu belirlenmiştir.

Tablo 1. Katılımcıların demografik bilgileri

\begin{tabular}{llll}
\hline \multirow{2}{*}{ Cinsiyet } & & Frekans & Geçerli yüzde \\
\hline \multirow{2}{*}{ Medeni durum } & Bayan & 65 & 67,0 \\
\hline \multirow{4}{*}{ Eğitim durumu } & Bekar & 32 & 33,0 \\
\cline { 2 - 4 } & Evli & 73 & 75,3 \\
\hline & Ilköğretim & 10 & 24,7 \\
\cline { 2 - 4 } & Lise & 62 & 10,3 \\
\cline { 2 - 4 } Ë̈n lisans & 6 & 63,9 \\
\cline { 2 - 4 } & Lisans & 18 & 6,2 \\
\cline { 2 - 4 } & Lisansüstü & 1 & 18,6 \\
\hline \multirow{2}{*}{ Spor yıl durumu } & Doğuştan & 73 & 7,0 \\
\cline { 2 - 4 } & Sonradan & 24 & 24,3 \\
\hline & $0-5$ yıl & 44 & 36,1 \\
\cline { 2 - 4 } & 6-10 yıl & 18 & 18,4 \\
\hline
\end{tabular}

Tablo 2. Katılımcılarn örgütsel stres alt boyutlar puan ortalamalarn

\begin{tabular}{lllll}
\hline & $\mathrm{N}$ & Ortalama & Std. Sapma & Std. Hata \\
\hline Seyirci davranışı & 97 & 3,0639 &, 62219 &, 06317 \\
\hline Antrenör davranışı & 97 & 3,0856 &, 40149 &, 04077 \\
\hline Yönetim ve finans & 97 & 3,0490 &, 75337 &, 07649 \\
\hline Sağlık ve beslenme & 97 & 3,1117 &, 53453 &, 05427 \\
\hline Karara katılım & 97 & 3,2345 &, 65829 &, 06684 \\
\hline Stres toplam & 97 & 3,0937 &, 31865 &, 03235 \\
\hline
\end{tabular}

Tablo 2'de sporcuların örgütsel streslerinin $(X=3,09)$ orta düzeyde olduğu görülmektedir. Örgütsel stres alt boyutları incelendiğinde antrenör davranışı alt boyutu $(X=3.08)$, yönetim ve finans alt boyutu $(X=3.04)$, sağlık ve beslenme alt boyutu $(X=3.11)$, seyirci davranış1 $(X=3,06)$ ve karara katılı alt boyutu $(X=3.23)$ olarak belirlenmiştir.

Tablo 3'te katılımcıların örgütsel stres düzeylerinin Cinsiyete Göre Farklılaşma Durumuna Ait bulgulara baktığımızda alt faktörlerde cinsiyete göre farklılık gözlemlenmiştir. Yapılan t-testi sonucunda erkeklerin $(\overline{X=3,15)}$ örgütsel stres antrenör davranışından kaynaklı alt boyut algıları kadınlardan $(\overline{\boldsymbol{X}}=2,94)$ istatistiksel olarak anlamlı derecede 
yüksek olduğu belirlenmiştir $(\mathrm{p}<0,05)$. Karara katılım alt boyut algilarının cinsiyete göre gruplar arasında fark istatistiksel olarak anlamlı bulunmuştur $(\mathrm{p}<0,05)$. Erkek $(\overline{X=3,30)}$ katılımciların karara katılımdan kaynaklı örgütsel stres puanları kadın $(\overline{X=3,08})$ katılımcılardan daha yüksek olduğu belirlenmiştir. Katılımcıların örgütsel stres algıları cinsiyete göre gruplar arasında fark istatistiksel olarak anlamlı bulunmuştur $(\mathrm{p}<0,05)$. Erkek $(\overline{X=3,16)}$ katılımciların örgütsel stres algıları kadın $(\overline{X=3,2,95})$ katılımcılardan daha yüksek olduğu belirlenmiştir

Tablo 3. Katılımcılarn örgütsel stres düzeylerinin cinsiyete göre farklılaşma durumuna ait bă̆ımsız örneklem t testi sonuçları

\begin{tabular}{|c|c|c|c|c|c|c|}
\hline & Cinsiyet & $\mathrm{N}$ & $\mathrm{X}$ & S.s & $t$ & $\mathrm{P}$ \\
\hline \multirow{2}{*}{ Antrenör davranışı } & Erkek & 65 & 3,1546 & ,40752 & \multirow{2}{*}{$-3,255$} & \multirow{2}{*}{,015 } \\
\hline & Kadın & 32 & 2,9453 & 35500 & & \\
\hline \multirow{2}{*}{ Seyirci davranışı } & Erkek & 65 & 3,1508 & 62753 & \multirow{2}{*}{$-1,898$} & \multirow{2}{*}{088} \\
\hline & Kadın & 32 & 2,8875 & ,58129 & & \\
\hline \multirow{2}{*}{ Yönetim ve finans } & Erkek & 65 & 3,1269 & ,84302 & \multirow{2}{*}{$-1,461$} & \multirow{2}{*}{,212 } \\
\hline & Kadın & 32 & 2,8906 & ,50176 & & \\
\hline \multirow{2}{*}{ Sağlık ve beslenme } & Erkek & 65 & 3,1590 & ,53880 & \multirow{2}{*}{$-1,245$} & \multirow{2}{*}{ 112 } \\
\hline & Kadın & 32 & 3,0156 & ,52082 & & \\
\hline \multirow{2}{*}{ Karara katılım } & Erkek & 65 & 3,3077 & 66844 & \multirow[t]{2}{*}{2,478} & \multirow{2}{*}{, 050} \\
\hline & Kadın & 32 & 3,0859 & 62090 & & \\
\hline
\end{tabular}

Tablo 4. Katılımcılarn örgütsel stres düzeylerinin engel durumlarına göre farklılaşma durumuna ait bağımsız örneklem t-testi sonuçları

\begin{tabular}{|c|c|c|c|c|c|}
\hline & Engel durumu & $\mathrm{N}$ & $\mathrm{X}$ & S.s & $\mathrm{p}$ \\
\hline \multirow{2}{*}{ Antrenör davranışı } & Doğuştan & 73 & 3,0705 & ,38449 & \multirow[b]{2}{*}{523} \\
\hline & Sonradan & 24 & 3,1312 & ,45512 & \\
\hline \multirow{2}{*}{ Seyirci davranışı } & Doğuştan & 73 & 3,0685 & ,58521 & \multirow{2}{*}{-900} \\
\hline & Sonradan & 24 & 3,0500 & ,73721 & \\
\hline \multirow{2}{*}{ Yönetim ve finans } & Doğuştan & 73 & 2,9452 & ,45500 & \multirow[b]{2}{*}{122} \\
\hline & Sonradan & 24 & 3,3646 & 1,25808 & \\
\hline \multirow{2}{*}{ Sağlık ve beslenme } & Doğuştan & 73 & 3,1553 & ,52362 & \multirow{2}{*}{-163} \\
\hline & Sonradan & 24 & 2,9792 & ,55672 & \\
\hline \multirow{2}{*}{ Karara katı } & Doğuştan & 73 & 3,1815 & ,62536 & \multirow{2}{*}{-168} \\
\hline & Sonradan & 24 & 3,3958 & ,74058 & \\
\hline \multirow{2}{*}{ Stres toplam } & Doğuştan & 73 & 3,0691 & ,27132 & \multirow{2}{*}{-186} \\
\hline & Sonradan & 24 & 3,1686 & ,43080 & \\
\hline
\end{tabular}

Katılımcıların örgütsel stres düzeylerinin engel durumuna göre istatistiksel olarak anlamlı derecede farklılaşmadığı bulgusuna ulaşılmıştır. 
Tablo 5. Katılımcıların örgütsel stres düzeylerinin medeni durumlarına göre farklılaşma durumuna ait bağımsız örneklem t-testi sonuçları

\begin{tabular}{|c|c|c|c|c|c|}
\hline & Medeni durum & $\mathrm{N}$ & $\mathrm{X}$ & S.S & $\mathrm{p}$ \\
\hline \multirow{2}{*}{ Antrenör davranışı } & Bekar & 73 & 3,0993 & ,38842 & \multirow{2}{*}{,- 559} \\
\hline & Evli & 24 & 3,0437 & ,44510 & \\
\hline \multirow{2}{*}{ Seyirci davranışı } & Bekar & 73 & 3,1041 & ,59732 & \multirow{2}{*}{,- 269} \\
\hline & Evli & 24 & 2,9417 & ,69151 & \\
\hline \multirow{2}{*}{ Yönetim ve finans } & Bekar & 73 & 3,0445 & 84017 & \multirow[t]{2}{*}{, 920} \\
\hline & Evli & 24 & 3,0625 & 39871 & \\
\hline \multirow{2}{*}{ Sağlık ve beslenme } & Bekar & 73 & 3,1438 & ,51991 & \multirow{2}{*}{,- 304} \\
\hline & Evli & 24 & 3,0139 & ,57718 & \\
\hline \multirow{2}{*}{ Karara katılım } & Bekar & 73 & 3,2123 & 66493 & \multirow{2}{*}{,- 565} \\
\hline & Evli & 24 & 3,3021 & ,64681 & \\
\hline \multirow{2}{*}{ Stres toplam } & $\underline{B e k a r}$ & 73 & 3,1064 & ,32484 & \multirow{2}{*}{,- 498} \\
\hline & Evli & 24 & 3,0552 & ,30235 & \\
\hline
\end{tabular}

Katılımcıların örgütsel stres düzeylerinin medeni durumlarına göre istatistiksel olarak anlamlı derecede farklılaşmadığı bulgusuna ulaşılmıştır.

Tablo 6. Katılımcıların örgütsel stres algı düzeylerinin ĕgitim değişkenine göre farklılaşma durumuna ait tek yönlü anova testi sonuçları

\begin{tabular}{|c|c|c|c|c|c|c|}
\hline & & $\mathrm{N}$ & Ort & Ss & $\mathrm{F}$ & $\mathrm{p}$ \\
\hline \multirow{4}{*}{ Antrenör davranışı } & İlk öğretim & 15 & 3,0600 & ,27162 & \multirow{4}{*}{,- 430} & \multirow{4}{*}{,732 } \\
\hline & Lise & 46 & 3,0597 & ,42357 & & \\
\hline & Önlisans & 15 & 3,2167 & ,26013 & & \\
\hline & Lisans & 21 & 3,1421 & ,42923 & & \\
\hline \multirow{4}{*}{ Sağlık ve beslenme } & İlk öğretim & 15 & 3,3167 & ,40407 & \multirow{4}{*}{677} & \multirow{4}{*}{, 568} \\
\hline & Lise & 46 & 3,0753 & ,56594 & & \\
\hline & Önlisans & 15 & 3,2222 & ,56437 & & \\
\hline & Lisans & 21 & 3,0877 & ,48549 & & \\
\hline \multirow{4}{*}{ Yönetim ve finans } & İlk öğretim & 15 & 2,8375 & ,53376 & \multirow{4}{*}{,- 745} & \multirow{4}{*}{, 528} \\
\hline & Lise & 46 & 3,1331 & ,87394 & & \\
\hline & Önlisans & 15 & 2,9583 & ,41583 & & \\
\hline & Lisans & 21 & 2,9145 & ,42092 & & \\
\hline \multirow{4}{*}{ Karara katılım } & İlk öğretim & 15 & 2,9750 & 62860 & \multirow{4}{*}{,- 825} & \multirow{4}{*}{483} \\
\hline & Lise & 46 & 3,2863 & 67728 & & \\
\hline & Önlisans & 15 & 3,0417 & ,40052 & & \\
\hline & Lisans & 21 & 3,2632 & 67430 & & \\
\hline \multirow{4}{*}{ Seyirci davranışı } & İlköğretim & 15 & 2,8600 & ,60406 & \multirow{4}{*}{$-1,186$} & \multirow{4}{*}{,319 } \\
\hline & Lise & 46 & 3,1387 & ,55467 & & \\
\hline & Önlisans & 15 & 3,1667 & ,59889 & & \\
\hline & Lisans & 21 & 2,8947 & 81478 & & \\
\hline
\end{tabular}


Katılımcıların örgütsel stres alt boyutları puan ortalamalarının eğitim değişkenine göre anlamlı bir farklılık gösterip göstermediğini belirlemek amacı ile yapılan tek yönlü varyans analizi (Anova)sonucunda grup ortalamaları arasında fark istatistiksel açıdan anlamlı bulunmamıştır $(\mathrm{p}>0,05)$.

Tablo 7. Katılımcıların örgütsel stres algı düzeylerinin spor yapma yılı değişkenine göre farkhlaşma durumuna ait tek yönlï anova testi

\begin{tabular}{|c|c|c|c|c|c|c|}
\hline & Spor & $\mathbf{N}$ & Ort & Ss & f & p \\
\hline \multirow{3}{*}{ Antrenör davranışı } & $0-5$ y1l & 35 & 3,0271 & ,51554 & \multirow{3}{*}{\multicolumn{2}{|c|}{$1,392,254$}} \\
\hline & 6-10 y1l & 44 & 3,0773 & ,32322 & & \\
\hline & $11-15 y 11$ & 18 & 3,2194 & ,29711 & & \\
\hline \multirow{3}{*}{ Sağlık ve beslenme } & $0-5$ y1l & 35 & 3,1286 & ,59007 & \multirow{3}{*}{-060} & \multirow{3}{*}{942} \\
\hline & 6-10 y1l & 44 & 3,0909 & 50891 & & \\
\hline & $11-15 \mathrm{y} 11$ & 18 & 3,1296 & 50989 & & \\
\hline \multirow{3}{*}{ Yönetim ve finans } & $0-5$ yil & 35 & 3,0143 & ,54719 & \multirow{3}{*}{,082 } & \multirow{3}{*}{921} \\
\hline & 6-10 y1l & 44 & 3,0824 & ,99597 & & \\
\hline & $11-15$ y1l & 18 & 3,0347 & 30258 & & \\
\hline \multirow{3}{*}{ Karara katılım } & $0-5$ yil & 35 & 3,2000 & ,73963 & \multirow{3}{*}{, 150 } & \multirow{3}{*}{,861 } \\
\hline & 6-10 y1l & 44 & 3,2330 & ,62737 & & \\
\hline & $11-15$ y1l & 18 & 3,3056 & ,59133 & & \\
\hline \multirow{3}{*}{ Seyirci davranışı } & $0-5$ y1l & 35 & 2,9486 & 69679 & \multirow{3}{*}{940} & \multirow{3}{*}{,394 } \\
\hline & 6-10 y1l & 44 & 3,1273 & ,54061 & & \\
\hline & $11-15$ yıl & 18 & 3,1333 & 65798 & & \\
\hline
\end{tabular}

Katılımcıların örgütsel stres alt boyutları puan ortalamalarının spor yapma yılı değişkenine göre anlamlı bir farklılık gösterip göstermediğini belirlemek amacı ile yapılan tek yönlü varyans analizi (Anova)sonucunda grup ortalamaları arasında fark istatistiksel açıdan anlamlı bulunmamıştır ( $\mathrm{p}>0,05)$.

\section{Tartışma ve Sonuç}

Araştırma örneklemini 1. Ligde oynayan toplam 97 goalball oyuncusunun oluşturduğu çalışmada, elit sporcuları için örgütsel stres ölçeği kullanılmıştır. Çalışmada temel olarak engelli sporcuların örgütsel stres faktörlerinden etkilenme düzeylerini ölçme, karşılaştırma çalışması gerçekleştirilmiştir. Yapılan çalışmada goalball oyuncuları üzerinde antre- 
nör davranışı, sağlık ve beslenme, yönetim ve finans, karara katılım ve seyirci davranışı stres faktörleri ölçülerek karşılaştırılmıştır.

Araştırmaya toplam 97 goalball oyuncusu katılmıştır. Cinsiyetlerine baktığımızda, sporcuların \%67'sini erkek, \%33'ünü ise kadın sporcular oluşturmaktadır. Medeni durumlarına göre \%75,3 sporcunun bekar, \%24,7 sporcunun evli, olduğu görülmektedir. Sporcuların \%10,3’u ilköğretim, \%63,9'i lise, \%6,2'si ön lisans, \%18,6’si lisans, \%2'si lisansüstü eğitimli sporculardır. Katılımcıların \% 75,3’ünü engel durumu doğuştan olanlar, \%24,7'sini sonradan olanlar oluşturmaktadır. Katılımcıların spor yılına baktı̆̆ımızda \% 36.' 'i 0-5 yıl, \% 44,4.'ü 6-10 yıl, \% 18,6's1 ise 11-15 yıl arasında olduğu belirlenmiştir.

Çalışmamızda, bulguların değerlendirilmesinden elde edilen sonuca göre katılımcıların Örgütsel stres alt boyutları incelendiğinde antrenör davranışı alt boyutu $X=3.08$, yönetim ve finans alt boyutu $X=3.04$, sağlık ve beslenme alt boyutu $X=3.11$, seyirci davranış $X=3,06$ ve karara katılı alt boyutu $\mathrm{X}=3.23$ olarak belirlenmiştir.

Bu sonuçlardan goallball oyuncularının en fazla etkilendikleri örgütsel stres faktörü karara katılım olduğu belirlemiştir. Bireylerin, örgütte yapılan işle ilgili kararların alınmasına katılma fırsatının verilmemesi, kendilerini ilgilendiren meselelerde fikirlerinin hiç sorulmaması ya da yapılan değişikliklerden haberdar olmamaları kendilerine verilen değer konusunda olumsuz düşüncelere sahip olmalarına sebep olabilir (Üzüm v.d. 2014). Özellikle engelli sporcuların bu düşüncelere sahip olmaları durumunda performanslarının olumsuz etkileneceği için yönetimin bu konuda daha hassas olması gerekmektedir.

Çeşitli finansal kaynaklar, özellikle yeterli miktarda sağlanmadı̆̆ında müsabakalarda sporcu için oldukça kötü duygular uyandırabilmektedir (Woodman ve Hardy, 2001). Görme engelli sporcularda yapılan çalışmada en az etkilenilen örgütsel stres kaynağı olarak yönetim ve finansa ulaşılmıştır. Yönetim ve özellikle finans motivasyon için önemli unsurlardandır, fakat çalışmanın örneklem grubu için diğer faktörlerden daha az etkiye sahip olduğu sonucuna ulaşılmıştır.

Çalışma sonucunda 1. Lig goalball oyuncularına ait bazı değişkenlerin; eğitim, medeni hal, engel durumu, örgütsel stres düzeylerini anlamlı düzeyde etkilemediği, fakat cinsiyet değişkeninin örgütsel stresi anlamlı derecede etkilediği bulunmuştur. Antrenör davranışı ve karara katılım 
faktörlerinden erkekler kadın sporculardan daha fazla etkilenerek örgütsel stres boyutları daha yüksek olarak bulunmuştur. Sporcuların antrenörlerinin kendilerine nasıl davrandıkları, antrenör ve sporcu arasında gerginlik, motive etmede ve saygıda eksiklik yaşadıkları önemli stres kaynaklarıdır (Woodman ve Hardy, 2001). Çalışmada erkek engelli sporcuların bu konularda kadınlardan daha fazla etkilendiği sonucuna varılmıştır. Benzer şekilde karara katılım faktörü kadın sporculardan daha fazla erkek sporcuları etkilediği sonucuna ulaşılmıştır.

Katılımcılarımızın maruz kaldıkları en yüksek örgütsel stres kaynağı karara katılımdır. Daha sonra beslenme ve sağlık, seyirci davranışı, antrenör davranışı, finans ve yönetim faktörleridir. Sporcu örgütlerin iş görenleri olarak görülmektedir. Sporcuların performansını en yüksek düzeyde olmasını sağlamak için, sporcuların motivasyonunu en üst seviyede tutmak gerekmektedir. Özellikle de engelli (goalball) sporcuların motivasyonunu etkileyen örgütsel stres kaynaklarının neler olduğunu belirleyip gerekli tedbirleri almalı başarı ve mutlu bir çalışma ortamı sağlanıp, performansları optimum seviyeye çıkartılmayı hedeflenmedir. 


\title{
EXTENDED ABSTRACT
}

\section{Analyzing Organizational Stress Behavior of First League Goalball Players}

\author{
Suzan Dal - Burçak Keskin - Eray Yurtseven - C. Nihal Yurtseven \\ Istanbul University-Cerrahpasa İstanbul University
}

The aim of our study is, the organizational stress levels of sports players with disabilities were measured and compared. Specifically, the stress factors of trainer behavior, health and eating, management and finance, agreeing decision, and audience behavior on goalball players were measured and compared. In this study, the stress levels of sports players with visual impairment based on the aforementioned stress factors were analyzed. This study is important because it shows the stress levels of sports players with disabilities by comparing variables such as family, trainer, teammate, and social environment stress. The study is also important because the results will provide valuable insights for managers and sport players. This study was designed to present the stressing factors in sports players with visual impairment.

It might be thought that sports players with disabilities (particularly Goalball players) might experience more organizational stress due to having higher stress factors from their physical disabilities. Because of this, precautions for identified stress factors can be taken and these could be compared to treatment and social inclusion of goalball players with sport.

Organizational stress resources change based on organization and the individual's role within the organization. For example, when the organizational stress resources of sports players were analyzed, there were different factors such as audience behaviour and trainer behaviour that are absent in many organizations. The purpose was to analyze which organizational stress resources of sports players with physical disability (goalball players) were associated with the most stress. In this study with a sample of 97 goalball players in first league, the organizational stress scale for elite sports players was examined by Üzüm H. et.al.(2010). This 
study found that upon analysing the sub-dimensions of organizational stress, the Behavior of Trainer mean score was $X=3.08$, the ManagementFinancing mean score was $X=3.04$, the Eating Healthy mean score was $X=3.11$, the Audience behaviour mean score was $X=3.06$, and the Agreeing Decision mean score was $X=3.23$. The total Cronbach's Alpha internal consistency of organizational stress scale was found to be $\alpha=0.823$. This result showed that this scale was sufficient to measure the organizational stress levels of sports players with physical disabilities. When the Cronbach's Alpha internal consistency values of sub-dimensions of the organizational stress scale were analyzed, the Trainer Behavior was found to be $\alpha=0.768$, the Management-Financing sub-dimension was found to be $\alpha=0.811$, the Eating Healthy sub-dimension was found to be $\alpha=0.825$, the Audience Behavior was found to be $\alpha=0.855$, and the Agreeing Decision sub-dimension was found to be $\alpha=0.771$. In this study, the Total Cronbach's Alpha internal consistency of organizational stress scale was found to be $\alpha=0.828$. The normal distribution (Shapiro-Wilk) test applied to the results of elite sports player organizational stress scale showed a significance value of 0.05 or more, indicating that the scale values showed normal distribution. The parametric measurements were used in this analysis. Frequency, t-test, and ANOVA statistics were used for the data analysis of this study. Based on these results, it was found that goalball players highest stress for the agreement on decisions subscore among the organizational stress factors. Because the thoughts of sports players with disabilities would negatively affect their performance, it is especially important to be gentle about this topic. Based on these results, it was found that goalball players highest stress for the agreement on decisions subscore among the organizational stress factors. Not giving opportunities for individuals to participate in decision making in the organization, not asking their ideas regarding events that concern them, or not notifying them about organizational changes might cause negative thoughts (Üzzüm et al. 2014). Because the thoughts of sports players with disabilities would negatively affect their performance, it is especially important to be gentle about this topic. When players do not have adequate financial resources, they might have more negative emotions during tournaments (Woodman and Hardy, 2001). It was found that the least effective organizational stress resources for 
sports players with visual impairment were management and finance. Management and finance are an important factor for motivation; however, in the sample of this study, it was found that this sub-dimension had little effect. The results of this study showed that certain variables of first league goalball players such as education, marital status, and disability type had no significant effect on organizational stress; however, sex had a significant effect on organizational stress. Male sports players were affected more than female sports players in terms of the trainer behavior and agreement on decisions subscores and showed higher organizational stress levels. How trainers behave to sport players, trainer-sports player tension, and lack of motivation and respect are among the most important stress factors (Woodman and Hardy, 2001). In this study, it was found that male sports players with disabilities were more susceptible than female sports players with disabilities. Similarly, in the agreement on decisions factor, male sports players were affected more than female sports players. The agreement on decisions subscore was the highest organizational stress experienced by the participants. This was followed by the subscores of health and eating, trainer behavior, audience behavior, and management and finance. Sports players are part of organizations. To achieve high performance from sports players, it is important to keep their motivation high. By identifying organizational stress resources of sports players with disabilities (specifically, for goalball), necessary precautions can be taken, successful and healthy work environment can be achieved, and performance can be increased to an optimum level.

\section{Kaynakça / References}

Ataman A. (2000). Görme engellilerin erken çocukluk eğitimi:Görme özürlülerin eğitimi. Içinde (s. 25-35.), Ankara:Körler Federasyonu Yayını No: 2.

Altungül, O. (2006). Futbol aktivitelerine katılanların kişilik özellikleri ışığında stres düzeylerinin belirlenmesi. Yüksek Lisans Tezi, Frrat Üniversitesi Sağlık Bilimleri Enstitüsü Beden Eğitimi ve Spor Anabilim Dalı, Elazı̆̆.

Balcıoğlu, İ. ve Doğrul, A.(2011). Profesyonel sporcularda stress. Türkiye Klinikleri Psikiyatri Özel Dergisi, 4(3), 59-65. 
Batıgün, A.D., Şahin, H., N., Demirel, E., K., (2011). Bedensel hastalıkları olan bireylerde stres, kendilik algısı, kişilerarası tarz ve öfke ilişkisi. Türk Psikiyatri Dergisi, 22(4), 245-54.

Cantwell, J., Muldoon, O. T., ve Gallagher, S. (2014). Social support and mastery influence the association between stress and poor physical health in parents caring for children with developmental disabilities. Research in Developmental Disabilities, 35(9), 2215- 2223.

Craft D.H. (1995). Visually impairments and hearing losses. adapted physical educatian and sport. In (Ed. J.P. Winnick), Human Kinetics Books Champaigne (p.143-166.), IIIinois.

Çukur, M. (2001). Örgütsel stres yönetimi (I). İSG İş Sağllğg ve Güvenliği Dergisi, 3, 7-10.

Ganley T.( 2001). Egzersiz ve çocuk sağlı̆̆ı. Spor ve Tip, 3-4, 41-47.

Graham, Helen, (1999). Stresi kendi yararınza kullanın. (Çev: M. SağlamT.Tezcan) İstanbul: Alfa Yayınları.

Lieberman L., ve Cowart, J. (1996).Games for people with sensory impairrnents: Strategies fonncluding individuals of aln ages. Champagne, IL: Human Kineties.

Laneioni G. E., Ollva, D., Braealente S, ve Hoopen G. (1996). Use of an aeoustie Orientation system for indoor travel with a spatially disabled blind man. Journal of Visual lmpairmentE Blindness, 90, 36-41.

Lieberman L. J., ve Taule, J. (1998) Including physieal fitness into the lives of individuals who are deaf-blind. Deaf-blind Perspeetives, 5(2), 6-10.

Tokoğlu, M. E., Aydıntan, B., Polat, M. ve Burmaoğlu, S. (2011). Bedensel engelliler ile bedensel engelli olmayanlarda örgütsel bağlllık ve iş tatmini: Kamuda bir araştırma. Akademik Bakış Dergisi, 23, 1-14.

Maggill, R. A., ( 1980). Motor leaming, Wm. C. Brown Comp. Publ., USA

O'Connell M. (2000). The effect of brailling and physical guidance on the selfefficacyof children who are blind. Unpublished master's thesis: State University of New York College at Brockport, NY,.

Özer, D. (2005). Engelliler için beden eğitimi ve spor. Ankara:Nobel Yayınevi.

Üzüm, H., Yalçin, H.B., Özen, G. ve Yüktaşir, B. (2014). Akademik yaşam ve örgütsel stresin kaynakları, Gazi Journal of Physical Education and Sport Sciences, 19(1-4), 23-35.

Woodman, T. ve Hardy, L. (2001). A case study of organizational stres in elite sports. Journal of Applied Sport Psychology, 13, 207-238. 
Yılmaz, A. Ve Ekici, S., (2003). Örgütsel yaşamda stresin kamu çalışanlarının performansına etkileri üzerine bir araştırma, Yönetim Ve Ekonomi Dergisi, 2, 1-9.

Şahin, H. (2005). Örgütsel stres. Maden Mühendisleri Odası. 09.08.2008 tarihinde $\quad$ www.maden.org.tr/resimler/ekler/B7e926154c1274e Ek.Pdf adresinden erişilmiştir.

Zedeck, S. (Ed),San Francisco, Calif.: Jossey- Bass, (1992), Ironson Gail, Work, "Job Stress And Health", Work, Families And Organizations.

\section{Kaynakça Bilgisi / Citation Information}

Dal, S., Keskin, B., Yurtseven, E. ve Yurtseven, C. N. (2019). 1.Lig goalball oyuncularının örgütsel stres davranışlarının incelenmesi. OPUSUluslararası Toplum Araştırmaları Dergisi , 13(19), 1958-1975. DOI: 10.26466/opus.591787 